\title{
NOTAS
}

\section{Más sobre los secretarios de Rubén Darío}

(Don Eduardo Lázaro y "Phocas el Campesino")

6 6T os secretarios de Rubén Darío" es el título de uno de los capítulos

de mi biografía del gran poeta. ${ }^{1}$ Allí explico que si Rubén tuvo a veces secretarias - la de la Dirección General de Correos de Buenos Aires y la de la Delegación de Nicaragua a la Conferencia Panamericana de Río de Janeiro- no le faltaron nunca, a su vez, secretarios a su servicio. Darío, dije, fue un secretario con secretarios.

Los secretarios del gran poeta nicaragüense no siempre ejercen funciones secundarias. Todos ellos, quien más, quien menos; alcanzan su pequeña parcela de inmortalidad. Algunos son tipos de contorno bastante brillante y de simpática juventud, incluso poetas y escritores; otros resultan oportunistas y aventureros. Pero todos poseen una gran corrección externa. Los hubo honoríficos, sólo por admiración a Darío, aunque momentáneos y circunstanciales. Los más duraderos eran los que recibían remuneración. Unos y otros fueron como escuderos de este poeta andante que junto a la mejor musa de carne y hueso, tuvo siempre una Dulcinea

1 "Este otro Rubén Dario". Premio Aedos de Biografía Castellana. Barcelona, 1960 [Cap. publicado antes en Papeles de Son Armadans, Madrid-Palma de Mallor$\mathrm{ca}$, junio de 1958, $\mathrm{N}^{\circ}$ XXVII, pp. 319-326. Hay tirada aparte de 50 ejemplares numerados]. 
abstracta e inmaculada - Nuestra Señora la Belleza- por la que libra las más descomunales batallas. Los secretarios de Darío son los que comparten con él la tarea burocrática de la diplomacia y de la correspondencia literaria y particular; los que, a veces, son padrinos de sus hijos e intervienen en la vida íntima del bardo rey; los que siempre que pueden le libran de la gente inoportuna, de los cobradores de deudas y le acompañan en muchas solemnidades. Muchos soñaron que al lado del maestro conseguirían una "Însula Barataria", y se contagiaron también del Ideal, y otros se separaron finalmente del poeta y tuvieron en su existir epílogos trágicos y oscuros.

Entre todos aquellos secretarios nombrados por mí había uno de perfil borroso, cuyo apellido ignorábamos y sólo conocíamos su nombre de pila que era el de Eduardo. Hoy, este caballero está identificado con plenitud, merced a una carta ya registrada y catalogada, cuyo texto viene a confirmar todo lo relativo a la enfermedad de "Phocas el Campesino", o sea el primer Rubén Darío Sánchez. Las noticias sobre don Eduardo eran todas marginales y no centrales. "Trabajó con el poeta en Madrid, seguramente entre I904 y I905", aseguré al redactar mi ya aludida biografía. Palacio Viso, el secretario de Vargas Vila, quien muchas veces actuó como secretario amistoso de Rubén, alude a don Eduardo en una carta: "A don Eduardo le saqué billete de tercera hasta Gijón".2 Iba, pues, don Eduardo a reunirse con su jefe en La Arena (San Esteban de Pravia) en Asturias el verano de I905. Por tradición oral, recogida de labios de Francisca Sánchez, puedo afirmar que don Eduardo tenía un ligero bigotillo y que acompañó a la madre de Phocas el Campesino en Navalsauz, cuando la mortal bronconeumonía del niño, que no era, como afirmó Francisco Contreras, el biógrafo chileno del poeta, de constitución raquítica. Contra este aserto está la afirmación del médico que asistió a Francisca et aste parto, o sea el canario don Luis Doreste Vila, quien me informó en una carta escrita desde el "Gabinete Literario de Las Palmas", el 9 de julio de I958, lo siguiente: "Recuerdo al Rubén Darío Sánchez, al 'Phocas el Campesino', nacido robusto, como presagio y mejor sino, por lo tanto, en cuanto a naturaleza, sangre y futuro". En la fotografía que tenemos de este niño, nacido en España por expreso deseo de su padre en 1903, parece en verdad un ángel jardinero. El niño se hallaba el 22 de diciembre de 1904 con su abuela. Juana en Navalsauz y "tan hermoso, decía ésta, que ya no puedo sostenerlo", y de paso enviaba unas coplas de aguinaldo para don Rubén, Francisca y María, a

2 Id. p. 297. 
la sazón en París. El ig de marzo de 1905, Juana del Pozo, continúa asegurando a sus hijas que el niño está hermosísimo, que "se escapa de casa y canta". ${ }^{3}$

Pero, al poco, tres meses después y en una de esas típicas alteraciones meteorológicas de Castilla, muy estimulantes, pero a veces fatales para los organismos, enferma y escapa por siempre de entre los suyos para cantar entre los serafines. En consecuencia, llegaron a Veneras No 4, entresuelo izquierda (hoy primero), el domicilio madrileño de Rubén Darío en I905, noticias alarmantes sobre Rubencito, que pasó algunas temporadas en ese piso. Partieron inmediatamente, la madre del niño, María, la hermana de Francisca y el secretario don Eduardo. Marcharían, sin duda, el cuatro o cinco de junio, y mientras abuela, madre y tía velaban al ángel, don Eduardo buscaría los médicos de los alrededores para ver de salvar al enfermo." Desdichadamente, todo fue inútil. Y, como digo en mi citada biegrafía, "Phocas" muere el to de junio de I905, como pude comprobar en el pequeño cementerio de Navalsauz en 1959, en la lápida del enterramiento.

Navalsao (sic) el 10 de Junio de 1905. Mi rèspetable y distinguido amigo: ayer 9, no escribí a Ud. por haber salido de aquí precipitadamente, porque el de cabecera pidió consulta puesto que el niño se agravó el Jueves por la noche de una manera alarmante. El Viernes hubo consulta opinando los tres médiccs que el niño estaba gtavísimo. Veremos a ver lo que resulta; creo que sea nada bueno.

Doña Francisca no se aparta de su hijo ni un instante, así como María. Sin más que manifestarle, reciba recuerdos de Da. Francisca y María. Afectos a mi sobrina Luisa, besos a Alberto y Ud. sabe puede mandar como quiera a su afmo. s. s.

Q. B. S. M.

Eduardo Lázaro.5

5 y 4 Archivo Rubén Darío. Se conservan, en el mismo pliego, dos misivas del 7 de junio, una de Francisca y ctra de don Eduardo, ambas dirigidas a Rubén Datío. Las dos hablan de que, según el médico, cuyo nombre no manifiestan, el niño mejora. Sin duda, ésta fue la mejoría de la muerte, como se dice en España.

Estar enfermo en Navalsauz debía y debe ser una cosa trágica, dada la carencia de facultativo, y hay que traerlo de otros lugares como San Martín del Pirnpollar, Cepeda de la Mora y Hoyo Casero. Así se explica que el día 7 don Eduardo entretuviese ingenuamente toda la tarde al médico de cabecera contándole cuentos, con el fin de que no se marchara de Navalsauz. En esta carta del 7 de junio de 1905 el secretario del poeta firma Eduardo y no nos descubre aún su apellido.

5. Don Eduardo, don Eduardo Lázaro, al emplear el topónimo del lugar donde se halla Rubencito, hace como los castellanos del siglo $x$, es decir, practica la asimilación au $>$ o: auro, oro; tauro, toro; Navalsauz $>$ Navalsao, con pérdida de la consonante final 
Don Eduardo, don Eduardo Lázaro, este es el secretario de Rubén cuyo apellido desconocíamos. El señor Lázaro fue quien enterró al primer Rubén Darío Sánchez, "a Phocas el Campesino" - a la manera de "Phocas le jardinier" de Rémy de Gourmont-sobre la fina tierra de Navalsauz. Don Eduardo, don Eduardo Lázaro, es el que deja dormir bajo los Ángeles, el que deja soñando bajo los Santos al delicioso "Phocas el Campesino". ¿Había muerto éste ya cuando don Eduardo le escribe a Rubén? Parece ser que sí, y que la carta es un puro eufemismo para no sobresaltar demasiado al padre y que éste no cayese en una de las graves crisis alcohólicas en que estos duros casos le sumían.

Los recuerdos a Luisa y los besos a Alberto, restan gravedad a la misiva y nos plantea el problema de quiénes son esos nuevos personajes que quedaron, sin duda, en Veneras $\mathrm{N}^{\circ} 4$. Al regresar a Madrid, según tradición oral recogida de labios de Francisca, y antes de tomar el "alcahuete" o coche de mulas que desempeñaba entonces la función de los actuales autobuses de línea, don Eduardo cayó al río Alberche, al cruzar el puente de madera que ya no existe. El río tiene allí escasa profundidad y el secretario no sufrió otra cosa que el fuerte remojón, continuando a Ávila sin cambiar de topa, a punto de coger otra bronconeumonía, como la que acabara con el dulce "Phocas".

Don Eduardo, don Eduardo Lázaro, comprendemos hoy, fue quien en la noche del 27 de marzo de I905, ante Juan R. Jiménez, Villaespesa, Vargas Vila y quizá Manuel Ugarte, entre otros, escribió la "Salutación del Optimista", que Rubén le dictaba paseándose como un oso —el poeta firmó "Ursus" en alguna ocasión- por el piso de Veneras 4, entresuelo izquierda, santuario de la Hispanidad. Don Eduardo Lázaro, quien en un departamento de tercera llegó en tren a Gijón y desde allí a La Arena en carruaje, cargado con los primeros ejemplares de los Cantos de vida y esperanza, que Darío dedicó a los amigos y a los críticos y cuya edición había cuidado Juan Ramón Jiménez. Don Eduardo Lázaro, quien en la próxima Cuesta de Santo Domingo, preguntaría en la primavera de 1905 , de parte de su jefe, por el estado de salud de don Juan Valera. Quien certificaría los artículos para La Nación y haría otros mil encargos que Rubén necesitase.

No cabe duda que a este secretario, don Eduardo, don Eduardo Lázaro, le tocó vivir junto a Darío el tiempo cenital del poeta y que si asistió a alguna de sus grandes desventuras íntimas, también estuvo presente en sus mayores triunfos literarios. Ya en Asturias, despachó de nuevo correspondencia con el poeta, copió varias crónicas para Buenos Aires y pudo testificar la presencia de Azorin en aquella costa, con un 
paraguas rojo. Supo de don Rafael Altamira, el gran historiador; de don José Buylla, un médico de Oviedo, admirador de Darío y de la oscuridad en pleno día con motivo del eclipse total de sol ocurrido el 30 de agosto y que Rubén comentó humorísticamente con la frase "desde que se pone el sol en todos los dominios de "España".

¿Sería don Eduardo, don Eduardo Lázaro, el inquilino de Veneras No 4 , entresuelo izquierda, quien realquiló a Rubén y Francisca seis o siete habitaciones de las catorce que posee la vivienda? ¿O sería Luisa, la sobrina de don Eduardo, la arrendataria del piso? Todo eso lo supieron bien, sin duda, Antonio Palomero, Francisco Villaespesa, Vargas Vila y Juan $R$. Jiménez, entre otros, pero parece ser que ninguno lo develó. De todos modos, don Eduardo, don Eduardo Lázaro, con Julio Sedano, con Juan Huertas, con Fernando Viller, con José Ma Torres Perona y con Enrique Guerra, por nơ hacer más fatigosa la enumeración, completa el pintoresco retablillo de los secretarios del poeta y asegura, con la trágica carta de referencia, su nítida personalidad de hombre correcto y subordinado.

\section{ANTONio OLIVER Belmás}

Seminario-Arcbivo Rubén Dario, Madrid. 
